\title{
Children and Mental Health Talk: Perspectives on Social Competence: An Epilogue
}

Karin Osvaldsson and J akob Cromdal

\section{Conference article}

Cite this conference article as:

Osvaldsson, K., Cromdal, J. Children and Mental Health Talk: Perspectives on Social Competence: An Epilogue, In Children and Mental Health Talk: Perspectives on Social Competence, Palgrave Macmillan; 2019, pp. 201-208. ISBN: 9783030284251 (print), 9783030284268 (e-book)

DOI: https:// doi.org/ 10.1007/978-3-030-28426-8_8

Series: The Language of Mental Health

Copyright: Palgrave Macmillan

The self-archived postprint version of this conference article is available at Linköping University Institutional Repository (DiVA):

http:// urn.kb.se/ resolve?urn=urn:nbn:se:liu:diva-162910 
8. Children and Mental Health Talk: Perspectives on Social Competence-An Epilogue

\author{
Karin Osvaldsson Cromdal
}

\author{
Jakob Cromdal
}

Linköping University

At first glance, "mental health talk" may have an adult ring to it, as indeed does the notion of "children's social competence". Evidently, both concepts are adult constructs and may have little to do with what children themselves orient to in the course of everyday life. The question then arises whether a book thus titled can tell us anything at all about the social worlds of children who are parties to talk that concerns their mental health and wellbeing. The plain answer is yes, but one will need to read beyond the title.

In fact, all the chapters offer insight into how children handle themselves in interactional encounters with adults, and occasionally also with other children (cf. Theobald \& Danby), where focus is on various aspects of the children's mental health and wellbeing. What is more, this insight is a product of rigorous analysis of interaction, informed by the sibling scholarly traditions of ethnomethodology and conversation analysis, EM/CA. This typically means that the insight on offer is highly praxeological (Mondada, 2011) that is, soundly anchored in close empirical observation of participants' own practices rather than generated by research hypotheses or coding schemes infused with, say, theories of child development. In this respect, the authors all align with Sacks' dictum to use "observation as a basis for theorizing" (1971/1992, Vol. 2. p. 420). 
However, careful commitment to key aspects of interactional organisation is not news - it is a long-standing trademark of EM/CA inquiry. Much less commonplace is what we learn from the book about mental health talk. It broadens the concept considerably, by showing that dealing with issues of mental health and wellbeing is sometimes the job of professionals who are not necessarily qualified in a mental health profession. To a large extent, this is due to EM/CA's rejection of a "container" view of context (also known as "bucket" theory of context, e.g., Goodwin \& Heritage, 1990), according to which a certain type of institutional talk would be determined by the institutional setting in which it takes place. Instead, EM/CA scholars point to the reflexive relationship between the setting and the actions that take place there. As the chapters of this book demonstrate, mental health talk with children does indeed take place in different clinical (Kawashima \& Maynard; O’Reilly, Kiyimba \& Hutchby) and clinically oriented research settings (Lamerichs, Alisic \& Schasfoort), just as it takes place in other institutional contexts such as police interrogations (Stommel \& Spooren), videosolicited research interviews with school children (Theobald \& Danby), or during urban excursions in preschool groups (Bateman \& Danby).

But what about children's social competence? A brief historical overview may help to situate the contribution of the book's chapters. It is thirty years since James and Prout's (1990) introduction of the "New social studies of childhood" (NSSC), a research programme that has had a strong impact on sociological understandings of childhood and proved consequential in establishing what is known as the "competence paradigm" (Hutchby and Moran Ellis, 1998) in contemporary child studies. NSSC offered a long-overdue reaction to the default developmental orientation to children's competence, as well as a prevailing conceptualisation of childhood as above all a period of socialisation, whereby adults secure 
the child's transformation from an "incipient being" (Durkheim, 1911) to a full member of society. It is worth noting that there had been earlier attempts in ethnomethodology (e.g., Mackay, 1974; Speier, 1970, 1976; Sacks, 1966/1992) to instate the child as an active agent in sociological work, by pointing to the adult bias hosted within socialisation theories. For instance, in an essay on adult-child interaction, which he described in terms of culture contact, Speier argued that

the classical formulation of socialisation [...] is an interpretive imposition of adult lay conceptions onto the data of childhood behaviours, taking, as it were, only half of the interactional picture into consideration. The children's half, that part of the interactional picture not represented by the ideology, has been left unformulated in the analysis. (1976, p. 99)

In a similar vein, Mackay (1974) proposed that

[children's] competence is not acknowledged within the normative approach because the study of socialisation takes the views of the dominant culture (adult) and proposes them as scientific findings. (p. 180)

This dominant adult culture is rooted in lay understandings of children - understandings that, according to Garfinkel, et al. (1962/1982), were heavily infused with a developmental stance to the conduct of children

Within that relationship [adults vs. children], which entails the adults' use of the developmental scheme as a part, children are naturally, normally, obviously, objectively, really and observably faulted speakers. Further, their faulted speech 
is observably the present phase of a projected and familiar course. They speak as they do, being on their way to speaking one day better than they currently do: one day they will speak like the adults. (p. 4)

In essence, this developmental "scheme" provides for a view of children as "adults-inbecoming" (Garfinkel, et al., 1962/1982, p. 2). As a product of socialisation theory and an almost mandatory developmental perspective, the adult bias in studies of children effectively denied the possibility of seeing their competence (see Cromdal, 2009, for a more recent sample). As it turned out, this critique of the state of affairs in social and behavioural studies of children was far before its time and did not gain much foothold outside ethnomethodology. Yet, decades later, the very same arguments echoed in James and Prout's prescription list for a new generation of social studies of childhood:

3. Children's social relationships and cultures are worthy of study in their own right, independent of the perspective and concerns of adults.

4. Children are and must be seen as active in the construction and determination of their own social lives, the lives of those around them and of the societies in which they live. (Prout \& James, 1990, p. 8)

There is, of course, a danger in a-priori ascriptions of competence of tipping the scales the other way, but at the very least the programmatic claims of NSSC sparked a sound discussion concerning the view of children in both sociology and psychology. In childhood psychology (Sommer, 2012) for instance, the universally acknowledged developmental theories are now being challenged and the psychological life of children and young persons is understood in 
its cultural and social context, rather than mapped onto an idealised developmental trajectory toward adulthood. Consequently, the image of the child as inherently fragile and lacking in various abilities is abandoned, without being replaced by an ideology of competence. Instead, the concept of the resilience is proposed, where childhood and children's individual experiences are always set in relation to the surrounding context (Sommer, 2012).

Two of the chapters in this volume examine aspects of social competence in the course of clinical assessment. Kawashima and Maynard focus on the local organisation of echolalia - a form of repetition, traditionally seen as an indicator of communicative impairment showing how its delivery resulted in a tweaking and expanding of the standardised testing sequences, allowing the child to produce relevant tasks and "adjust to the requirements of the institutional setting" (p. XX). The chapter by O'Reilly, Kyiumba and Hutchby, focuses on young clients' problem presentations in mental health assessments. The client's competence was initially presumed, and recognised, when the accounts of trouble were grounded in the client's own emotions and experiences - their personal epistemic domain. However, when the accounts intersected with the clinical epistemic domain, for instance if clients used a diagnostic term to describe their problems, clinicians would inquire the details of that account. At the crossroads of personal and professional knowledge then, young clients were simultaneously credited with social competence as well as held accountable for aspiring to use medical terminology.

In the research interviews examined by Lamerichs, Alisic and Schasfoort, the interviewing psychologist, who was trying to elicit the children's perspectives on traumatic events in the 
past, faced an interactional challenge: the respondents were reluctant to align with the presuppositions hosted in the interviewer's questions. The children's social competence that emerges from the analysis, is not about their ability to describe and reflect on their problems but in the various techniques they deployed to control the conversational topics and to construct a narrative in which the psychological consequences of the traumatic event were downplayed (cf. Evans and Maines, 1995). Narrative competence is also in focus in the police interviews with child witnesses of sexual abuse examined by Jol, Stommel and Spooren. Here, we learn how children report having tricked the alleged sex offender in various ways that demonstrate high degree of creativity, social competence and situational awareness. In the context of sexual abuse and violence, there is a common belief - known as the ultimate resistance myth (Estrich, 1987) - that true victims always put up extreme resistance. According to the authors, by presenting the police officers with narrative accounts that highlight their agency and the rationality of misleading the alleged offender, the children orient themselves to this expectation and pre-empt the possibility of being blamed for not having resisted more forcefully.

When a natural disaster hits a community, adults and children alike are affected. The chapter by Bateman and Danby examines how teachers and children at a preschool in Christchurch (New Zealand) engage in working through the experience in the aftermath of the recent earthquakes, while walking around in the city. The analysis shows how the material environment is brought about in situ to make space for even the smallest of children's reflections about the devastating consequences of the catastrophe. In the chapter by Theobald and Danby, the setting is a research group interview with pre-school children where the researcher has asked the participating children to reflect upon an earlier video- 
recording of a play situation. While watching the video, the children produced different opinions about what really happened and how the participants had really felt during the play. With the other chapters in mind, the analysis takes a somewhat different tack on mental health talk, showing how the researcher seeks to steer the interaction away from reflecting upon the play events, to handling the emerging situation so that a traumatising experience of the interview is avoided.

Although the notion of children's social competence is being iterated throughout this book, it is important, as some of the professional commentaries remind us, to bear in mind that mental health talk is an engagement of at least two parties, both bringing to the event their traits, experiences and competencies, as well as presuppositions concerning the competencies of the other (cf. Waksler, 1986). As we learn from several studies in this book, the professionals skillfully work to enhance children's participation in the interaction by exploiting the conversational machinery described by Sacks et al. (1974), to project and make conditionally relevant certain courses of actions in the subsequent turns at talk. The studies in this book thus avoid focusing single-mindedly on the one side, recognising it a shaky ground on which to build an understanding of any professional practice.

Crucially, the EM/CA approach adopted in the analyses may safeguard against overembracing the "competence paradigm" concerning the status of children as well as offering important theoretical leverage to a sociological understanding of institutional practice. Its approach to social interaction is participant-oriented and, at the same time, free from analytically intuitive lifespan categories. Preschoolers, adolescents, 40-somethings or gold agers alike are treated in the first place as participants to interaction, relieving the 
analysis of the - often unreflected - burden of premature categorisation. This does not suggest that analysts are ignorant of the possible relevance of cognitive functioning - and whatever competence, power, experience and what not, that may be conventionally associated with it - only that such status is analytically treated as an issue of membership categorisation, that is, a strictly interactional achievement.

What is at stake here for those taking a scholarly or professional interest in work with children's mental health and wellbeing is the relevance and status of child-ness and adultness, of lay-ness and professional-ness, of social competence and empathy in the situated conduct that constitutes this work. With its Schutzean heritage, EM/CA treats social reality as an issue of intersubjective relationships. Such relationships are products of "the reasoning structures and conventional member-orientations involved in [...] empirically observed courses of social interaction" (Coulter, 1979, p. 20). Of course, the enterprise does not allow us to understand what it may feel like to be a child client or an adult professional in a diagnostic, therapeutic or counselling session focusing on one party's traumatic experience or some other aspect of mental health. What it does promise, is to demonstrate how subjective matters are explicated and made sense of by other parties and how such sensemaking bears on the work being carried out. In the course of analysis, we often get to learn a thing or two about the institution in which that work takes place.

\section{References}

Coulter, J. (1979). The social construction of mind. Studies in ethnomethodology and linguistic philosophy: London: Macmillan.

Cromdal, J. (2009). Childhood and social interaction in everyday life - An introduction. Journal of Pragmatics, $41,1473-1476$. 
Durkheim, E. (1911/1979). Childhood. In: Pickering, W.S.F. (Ed.), Essays on Morals and Education. Routledge \& Kegan Paul, London.

Estrich, S. (1987). Real rape. Cambridge (Mass.): Harvard UP.

Evans, W. J. \& Maines, D.R. (1995). Narrative Structures and the Analysis of Incest. Symbolic Interaction, 18(3), 303-322.

Garfinkel, H., Girton, G., Livingston, E., \& Sacks, H. (1962/1982). Studies of kids' culture and kids' talk. University of California, Los Angeles. Unpublished manuscript.

Goodwin, C. \& Heritage, J. (1990). Conversation analysis. Annual Review of Anthropology, 19, 283-307.

Hutchby, I., \& Moran-Ellis, J. (1998). Children and social competence : arenas of action (Eds.), London: Falmer.

James, A., \& Prout, A. (1990). Constructing and reconstructing childhood : contemporary issues in the sociological study of childhood (Eds.), London: Falmer.

Mackay, R. W. (1974). Conceptions of children and models of socialization. In R. Turner (Ed.), Ethnomethodology. Harmondsworth: Penguin.

Mondada, L. (2011). Understanding as an embodied, situated and sequential achievement in interaction. Journal of Pragmatics, 43, 542-552.

Prout, A. \& James, A. (1990). A New Paradigm for the Sociology of Childhood? Provenance, Promise and Problems. In: A. James \& A. Prout (Eds.), Constructing and reconstructing childhood: contemporary issues in the sociological study of childhood. London: Falmer.

Sacks, H. (1966/1992). Lectures on conversation, Vol 1. Oxford: Blackwell.

Sacks, H. (1971/1992). Lectures on conversation, Vol 2. Oxford: Blackwell.

Sacks, H., Schegloff, E. A., \& Jefferson, G. (1974). A simplest systematics for the organization of turn taking for conversation. Language, 50, 696-735.

Sommer, D. (2012). A childhood psychology: young children in changing times. Basingstoke: Palgrave Macmillan.

Speier, M. (1970). The everyday world of the child. In: J. Douglas (Ed.), Understanding everyday life. Chicago: Aldine.

Speier, M. (1976). The child as conversationalist: Some culture contact features of conversational interactions between adults and children. In M. Hammersley \& P. Woods (Eds.), The process of schooling (pp. 98-103). London: Routledge and Kegan Paul.

Waksler, F. C. (1986). Studying children: Phenomenological insights. Human Studies, 9, 71-82. 